\title{
Adjectival agreement in Middle and early Modern Welsh native and translated prose
}

\section{Meelen, Marieke}

2020-01-01

Meelen , M \& Nurmio , S M 2020 , ' Adjectival agreement in Middle and early Modern Welsh native and translated prose ' , Journal of Celtic Linguistics , vol. 21 , no. 1 , pp. 1-28 . https://doi.org/10.16922/jcl.21.2

http://hdl.handle.net/10138/332072

https://doi.org/10.16922/jcl.21.2

cc_by_nc_nd

acceptedVersion

Downloaded from Helda, University of Helsinki institutional repository.

This is an electronic reprint of the original article.

This reprint may differ from the original in pagination and typographic detail.

Please cite the original version. 


\title{
Adjectival Agreement in Middle and Early Modern Welsh Native and Translated Prose
}

\author{
Marieke Meelen \& Silva Nurmio \\ University of Cambridge \& University of Helsinki
}

This paper investigates adjectival agreement in a group of Middle Welsh native prose texts and a sample of translations from around the end of the Middle Welsh period and the beginning of the Early Modern period. It presents a new methodology, employing tagged historical corpora allowing for consistent linguistic comparison. The adjectival agreement case study tests a hypothesis regarding position and function of adjectives in Middle Welsh, as well as specific semantic groups of adjectives, such as colours or related modifiers. The systematic analysis using an annotated corpus reveals that there are interesting differences between the genres, as well as between individual texts. However, zooming in on our adjectival agreement case study, we conclude that these differences do not correspond to many of our hypotheses or assumptions about how certain texts group together. In particular, no clear split into native and translated texts emerged between the texts in our corpus. This paper thus shows interesting results for both (historical) linguists, especially those working on agreement, and scholars of medieval Celtic philology and translation texts.

\section{Introduction}

In order to study the linguistics of Middle Welsh, we depend on written texts. These are all written to varying degrees in a formal literary register, and the study of linguistic features often involves uncertainty between regarding something as really reflecting the spoken, idiomatic language of the time, or being a peculiarity of literary stylistics. Rodway's (2013) work has advanced our knowledge of the linguistic differences between prose and poetry as regards the Middle Welsh verbal system. This paper deals with the genre and register of texts translated 
into Middle and Early Modern Welsh from medieval Latin or French, compared to texts of native origin such as the Four Branches of the Mabinogi. ${ }^{1}$ With a sample of texts, we test the hypothesis that translated texts feature a higher proportion of adjectival number agreement than native prose. We also test a related observation often made, namely that translated prose has a higher proportion of attributive adjectives preceding the noun they modify, instead of the regular order of noun followed by the adjective, e.g. ci bach [dog small] 'a small dog'. Preposing is regular for a small group of Welsh adjectives, e.g. hen 'old' (hen gi 'an old dog'),

while it is possible with others for stylistic or other marked purposes. A small group of adjectives have a different meaning depending on their position; e.g. unig means 'unique, only' when placed before the noun, and 'alone, lonely' when it is post-nominal (see Thomas 2006: 209-10). We examine whether the order adjective + noun is indeed a strong feature of translated prose, and whether number agreement and the position of attributive adjectives is related; for instance, are preposed adjectives more likely to agree in the plural than those in the regular post-nominal position? This is a methodological paper intended as a model for further research, and we refrain from commenting on issues such as authorship and date of texts. We hope that work of this kind can eventually be incorporated into these debates, once we have established a basic picture. Likewise, traditional labels of texts are used for convenience and without implying any opinions about them.

\subsection{Agreement with adjectives in Welsh}

Number agreement of attributive adjectives is optional in all attested periods of Welsh. With predicative adjectives agreement is rarer, but it does occur in Middle Welsh, as we will see below. By attributive agreement, we refer to examples such as ci bach 'a small dog' above, while an example of predicative use is mae'r ci yn fach [is-the dog PRT small] 'the dog is small'. Comparative and superlative forms of adjectives never exhibit plural agreement and are 
therefore left out of the present discussion. For Modern Welsh, Borsley et al. (2007: 179) state that number agreement never occurs in predicative position, although there are some exceptions (see section 4.2). A terminological note on agreement is needed here. Borsley et al. (2007: 178) describe adjectives that lack agreement in a noun phrase as 'general', rather than 'singular', e.g. llygaid gleision / glas [eyes blue.PL / blue.GENERAL] 'blue eyes'. We follow this convention throughout this paper. A related question is whether we should make a distinction between adjectives for which plural morphology is attested and those for which it is never attested in the written records of Middle and Early Modern Welsh. Such a distinction does seem to exist and could be confirmed for Modern Welsh by speaker judgements. This is, however, not possible for the earlier stages. We have therefore avoided making such a distinction in the present paper and assume that any adjective can, in theory, have plural agreement.

It is clear that some adjectives agree in the plural more commonly than others. One adjective is usually stated to have compulsory agreement, namely arall 'another, other', pl. eraill (MW ereill). This is still virtually the case in Present-day Welsh, although a search through the $C E G$ corpus reveals a few non-agreement examples out of 1467 tokens of arall, e.g. diwrnodau arall [day.PL other.GENERAL] 'other days'. ${ }^{2}$ With other adjectives, the situation varies. Some, like bychan 'small', pl. bychain (MW bychein), very commonly agree in number especially in Middle Welsh, and to some extent still in Modern Welsh (its variant bach 'small' has no plural form). Likewise, ifanc/ieuanc 'young', pl. ifainc/ieuainc (MW ieueinc) still commonly agrees in number (Thomas 2006: 201). Adjectives for colours are another commonly agreeing group, and these have a separate sub-class where the plural adjective has been lexicalised, usually in words denoting plants or berries, e.g. mwyar duon [berry.PL black.PL] 'blackberries' (see Awbery 2014). A quantitative survey of the agreement 
pattern of different adjectives in Present-day Welsh, both spoken and written, remains a desideratum.

Breton and Cornish present a somewhat different situation where adjectival number agreement has virtually disappeared by the medieval period. There are just a few exceptions, most notably the adjective 'small' which is suppletive in number in Middle Breton and Middle Cornish: B sg. bihan, pl. munut and C sg. byhan, pl. munys (Jørgensen 2012; Nurmio 2017 and forthcoming). We do not discuss Breton and Cornish further in this paper. An interesting question for future comparative research on the Brittonic languages would be why the loss of agreement proceeded differently in Breton and Cornish compared to Welsh.

\subsection{Substantival adjectives in Welsh}

Adjectives can also be used as nouns in Welsh, both in the singular and plural. In some instances, e.g. $y$ claf 'the ill person, patient' (pl. $y$ cleifion), the singular can be used as a noun and we follow Borsley et al. (2007: 182-3) in treating these as nouns which are homonymous with the adjective synchronically (while related to them diachronically), rather than attributive adjectives agreeing with a zero head noun. With other adjectives, substantival usage is only possible with the plural, with no corresponding singular, e.g. deallusion 'intellectuals' (from deallus 'intelligent; intellectual') (Borsley et al. 2007: 182-3). This is similar to the English use of the rich, the poor, etc. which likewise lack singulars (**a rich, a poor). We analyse substantival adjectives in Welsh as being nouns synchronically, although they are historically related to the corresponding adjective, and exclude them from the current discussion which focuses on adjectival number agreement with a head noun.

\subsection{Welsh translated texts}


Modern-day editors of medieval Welsh translated texts have tended to highlight their differences from native prose. Luft (2016) looks in detail at these editorial attitudes and shows that they range from treating the language of translations as inferior or odd by native standards to highlighting the skill of the translators. What is common to such discussions is the idea that we can tell from the style that a text is a translation, even though there are some presumed translation texts, or texts including translated or adapted material, which lack a known source, such as Ymborth yr Enaid (see Daniel 1995: xlii-1). Many editors highlight such linguistic features as plural adjectives and the use of the demonstratives yr hwnn/yr honn/y rhai 'this.MASC/this.FEM/these' as relative markers (Evans 1964: 69, Luft 2016: 171, 176). There seems to be a consensus that translation texts comprise a genre or register of medieval Welsh literature, with distinct features that separate it from other text types. However, so far there have been few studies which attempt to quantify these features in comparison with native prose, and the observations remain somewhat impressionistic. It is important to understand the style of these texts if we are to use them as linguistic evidence, since some features may reflect a usage removed from the contemporary spoken language.

Middle Welsh translation texts have recently been the subject of increased interest. The texts in Llyfr Ancr Llanddewibrefi, mostly translations from Latin, are the subject of the project 'Translations as language contact phenomena: studies in lexical, grammatical and stylistic interference in Middle Welsh religious texts', conducted by Erich Poppe and Elena Parina at the University of Marburg. As a contribution to a finer-grained description of the stylistic registers of Middle Welsh prose, they approach these texts from a double perspective, focusing both on the frequency and distribution of the 'traces of translation' that have been posited in previous discussions and on the evidence for the translators' 'native' linguistic competence and sensibility (see Parina 2017 and Poppe 2016 for some preliminary results). Plein \& Poppe (2014) conducted a quantitative study of the patterns of verbal agreement in Historia Gruffud 
vab Kenan, a translation of the Latin Vita Griffini Filii Conani. They conclude that this text shows a somewhat higher percentage of plural subject-verb agreement compared to the normative expectations of native prose, mostly in verb-initial and relative clauses. However, this remains a tentative finding since we know that even native prose allows for variation in agreement, and Plein \& Poppe stress the need to study the agreement patterns of Middle Welsh, both native and translated, in more detail (see also Poppe 2014 and Harlos et al. 2014).

Nurmio (forthcoming) compares the language of four Middle Welsh translations of Geoffrey of Monmouth's Historia Regum Britanniae, known in Welsh as Brut y Brenhinedd (often Brutiau for short), focusing on the three earliest versions from the mid- to late thirteenth century (NLW Peniarth 44, NLW Llanstephan 1 and NLW 5266 (Brut Dingestow)) and one slightly later one (BL Cotton Cleopatra Bv, fourteenth century). While not a quantitative survey of agreement, she observes that these translations feature plural agreement for adjectives which are never or rarely attested with plural agreement in native texts, e.g. kywarssanghedygyon 6ydynoed [trampled upon.PL army.PL] 'trampled-upon armies' (NLW Llanstephan 1, see Isaac et al. 2013); the adjective cyfarsangedig/cywarsangedig 'trampled upon, oppressed' is never found in the plural in native texts. Similarly, we find many plural adjectives in the Old Welsh glosses which are hapax legomena, e.g. dubeneticion abalbrouannou [cut-off.PL Adam's apple.PL] 'cut-off Adam's apples' (Falileyev 2000: 51), possibly containing the plural form of an adjective in -edig formed from the verbal stem difyn- 'to dissect, cut to pieces'. Nurmio (forthcoming) argues that Old Welsh glosses should be treated as part of the discussion on 'translation style', since we find many similarities between them and the medieval translated prose texts.

Section 2 introduces the dataset we use to test our hypothesis that number agreement is more common in translated prose, and the second hypothesis that preposing attributive adjectives is also more common than in native texts. Section 3 describes the methodology of 
this study. Section 4 is a detailed overview of the results, with data for different texts and taking into account both agreement and the position of the adjective in the case of attributive adjectives. In section 5 we present an analysis of the results, before summing up the findings and outlining some questions for further research in section 6.

\section{Dataset}

The dataset is divided into two groups: native prose and translated prose. Native prose comprises the so-called Mabinogion corpus, found in the White Book of Rhydderch (NLW Peniarth $4 \& 5$, dated c. 1350) and the slightly later Red Book of Hergest (Jesus College Oxford 111, dated c. 1385). This corpus consists of eleven narrative tales, usually dated 'between the end of the eleventh and the beginning of the fourteenth centuries'; the details of their date remain debated (Davies 1998: 134; Rodway 2013: 1). The first four tales are known as the Pedeir Keinc, the 'Four Branches' (Williams 1930). These include narratives named after the four major characters: Pwyll, Branwen, Manawydan and Math. Then there are three Arthurian tales about Peredur, Owain and Gereint, traditionally labelled the 'Three Romances' although this label is contested (see esp. Lloyd-Morgan 2004). Arthurian literature of this kind featuring the same protagonists is found in other European languages, including Chrétien de Troyes's French versions. The relationship of the Welsh Romances to their French counterparts has been long debated, and the current consensus treats them as native compositions but ones influenced to some extent by the French ones (see e.g. Lloyd-Morgan 1991; see also Poppe \& Reck 2006 \& 2008, Vitt 2010, and Cordo-Russo 2014 on the Welsh Charlemagne cycle). We include the Romances tentatively in the native corpus, but will also discuss them separately in section 4 to see whether they differ significantly from the other native texts. We then have four further native tales: Culhwch ac Olwen, Breudwyt Maxen ('The Dream of Macsen'), Breudwyt Ronabwy ('The Dream of Rhonabwy') and Cyfranc Lludd a Llefelys ('The Tale/Encounter of 
Lludd and Llefelys', which also occurs inserted into the NLW Llanstephan 1 version of Brut y Brenhinedd and other later versions). ${ }^{3}$ Culhwch ac Olwen is usually taken to be somewhat earlier linguistically than the other tales of the Mabinogion corpus (see Rodway 2013: 1, fn. 2) and we analyse this tale separately in section 4 to see whether it differs from the other texts as regards adjectival agreement. For our annotated corpus, only the edited versions of the White Book of Rhydderch texts have been used. ${ }^{4}$

The translated prose comprises two sets of texts: excerpts from the 1588 Welsh translation of the Bible by William Morgan, and Buchedd Dewi ('The Life of St David') from Oxford Jesus College MS 119 (Llyfr yr Ancr) dating from 1346 (Huws 2000: 59). The Bible excerpts are narrative passages from both the Old and the New Testament. They include Joseph's and David's tales (Genesis 37-45 and 1 Samuel 16-18), fragments of the gospels (Matthew) and Paul's letters to the Corinthians. The texts were translated directly from the Hebrew and Greek originals. No significant difference between the Old and New Testament have so far been noted to be specifically due to translation from each of these languages, but a thorough comparative investigation of this kind is still a desideratum. Buchedd Dewi from Oxford Jesus College MS 119 is one of many versions of the life of this famous saint (Evans 1965: xxxiv, fn.1).

The Bible translation dates from around the start of the Early Modern Welsh period, usually taken to begin at c. 1500 (Russell 1995: xviii). This, and also the mid-fourteenthcentury Buchedd Dewi, are therefore somewhat later in date than the native corpus, and this needs to be borne in mind in the comparisons that follow. These texts were used for this study due to the material being available and previously tagged (see section 3), while we currently lack tagged corpora of earlier translation texts. The transition from Middle to Early Modern Welsh was slow and gradual, and thus texts from around the somewhat arbitrary cut-off point of the year 1500 are still interesting for studies focusing on Middle Welsh. The Bible translation 
may also differ from other types of translated texts by being affected to a greater extent by potential religious or political motivations of the translators and scribes. Future work should, of course, test the findings of this study against earlier Middle Welsh translation texts once tagged corpora become available.

\section{Methodology}

The eleven tales of the Mabinogion corpus were tagged using a memory-based part-of-speech tagger (cf. Meelen 2016 and Meelen forthcoming). This detailed morpho-syntactically annotated corpus allows for automatic searches of combinations of plural noun phrases, numerals and adjectives. The translated prose corpus (excerpts from the 1588 Bible and Buchedd Dewi) was also tagged using this method. We started by collecting all examples of plural nouns modified by adjectives, either in the attributive or predicative position. The adjectives were tagged for agreement and non-agreement. Since we predicted that specific lexemes might behave differently from the norm, separate statistical analyses were carried out on them: arall 'another, other', bychan 'small', ifanc/ieuanc 'young' and adjectives for colours, such as coch 'red', $d u$ 'black', etc. These appear to have plural agreement very often in Middle Welsh and we set out to test this observation.

In the following section, we compare the following points in native prose and translated prose:

- what is the overall pattern with agreement vs. non-agreement of adjectives with plural head nouns?

- does the function (attributive vs. predicative) correlate with agreement?

- does the position of the adjective (pre- or post-nominal) correlate with agreement?

- do some adjectives have agreement patterns that deviate from the average (arall 'another, other', bychan 'small', ifanc/ieuanc 'young' and adjectives for colours)? 
- do multiple adjectives modifying one noun sequentially (e.g. the big white dog) all agree or not?

- is there variation between texts? Is there a difference between translated and native texts? Are the three 'Romances' different from the other texts? Is Culhwch ac Olwen different from the rest?

\section{Results \& discussion}

\subsection{Overall agreement patterns in native and translated prose}

Looking at the absolute numbers ${ }^{5}$ of plural head nouns with adjectives (Fig. 1) ${ }^{6}$ and the percentages (Fig. 2), the number of instances of plural agreement ('yes' in the chart) is generally quite low at 27\% (102/372). There is no text in which the number of plural adjectives modifying plural head nouns is higher than the number of adjectives without plural agreement marking. This is in accordance with our assumptions regarding native Middle Welsh prose. There are striking differences, however, between the native tales: Peredur shows a high number of plural adjectives (29 in total), which is almost the same as the number of adjectives that do not show number agreement (30 in total). Compared to most other native prose texts and also the other Romances, Owein and Gereint, this is an extraordinarily large percentage. This result is even more interesting considering the commonly accepted 'fluid' textual history of Peredur compared to other texts of the Mabinogion corpus (see Vitt 2010 for a comparison of different manuscript versions and their significant differences, and Charles-Edwards 2001: 26-37 and Russell 2003: 60-4 for detailed analyses of the 'fluidity' of Peredur and its implications for its textual history). Compare also Rodway (2013: 21) who questions the usefulness of the 'fixed' vs. 'fluid' distinction, given that behind texts that appear 'fixed', there may still be a fluid transmission history. According to Charles-Edwards (2001: 26), the White Book version of Peredur, which we used in our corpus, is the more 'polished' version of the text. Furthermore, 
he argues that there is a major difference between a 'fluid' text like Peredur and other more fixed texts, such as the translated Brut y Tywysogion: '[...] there is a real difference between textual traditions in which the needs of professional competence and competition were the impulses behind innovation [as with Peredur] and those in which they were not [as with Brut y Tywysogion]' (Charles-Edwards 2001: 37; see also Vitt's (2010) discussion on 'fluidity' and its repercussions for stemmatics of the text). In other words, variation in fixed texts is more likely due to scribal errors or different copying strategies, while in fluid texts variation may be more deliberate due to the desire to innovate the text. Russell (2003: 64) draws attention to another interesting point about Peredur, which has not received much attention in the scholarship; in Peniarth 7, this tale sits alongside texts which are all translations. Does this indicate that Peredur was somehow perceived as belonging with them? While our study cannot answer such a question, it is nevertheless noteworthy that this text has a high percentage of plural adjectival agreement, a feature thought to characterise some translation texts, as discussed above in the Introduction. ${ }^{7}$

Of the other texts of the rest of the Mabinogion corpus, only Breudwyt Ronabwy comes close to Peredur with 13 instances (30\%) of agreement and 30 of non-agreement. Lludd appears to have a high percentage of agreement, but note the low number of absolute tokens (three out of seven examples, or 43\%, have agreement). Two tales, Branwen and Manawydan, have no examples of plural agreement. However, it is crucial to look at the absolute numbers again to put this in context; the total of noun phrases where agreement would in theory be possible is low in each (12 in Branwen, 4 in Manawydan).

If we take a closer look at the 29 examples in Peredur, we notice that there is a lot of repetition in the numerous descriptive passages of this tale, e.g. deu vann gochyon [two tip/area red.PL] 'two red spots' (occurs four times) and defeit gwynyon [sheep.PL white.PL] 'white sheep' (occurs three times). ${ }^{8}$ In the 1588 Bible translation of the Joseph story, in particular, the 
description of grains in his dreams is often repeated with the same lexemes: breiscion 'large, thick.PL' vs. culion 'lean.PL' and teneuon 'thin.PL'. Most of these passages furthermore contain adjectives of colour, which commonly agree (see section 4.5 below for further discussion of colour adjectives). Such a high degree of variance between native prose texts makes it difficult to compare these directly with the two translated texts under investigation. The translated texts also show variation between themselves: the 1588 Bible translation has a high percentage of agreeing adjectives (28/63, or 44\%) but Buchedd Dewi does not (only 4/30, or $13 \%$, of adjectives have agreement). In summary, no clear difference between native and translated texts appears from the comparison of absolute numbers of plural agreement examples. Instead, we see considerable variation between texts, but not according to a clearcut native vs. translated distinction. 


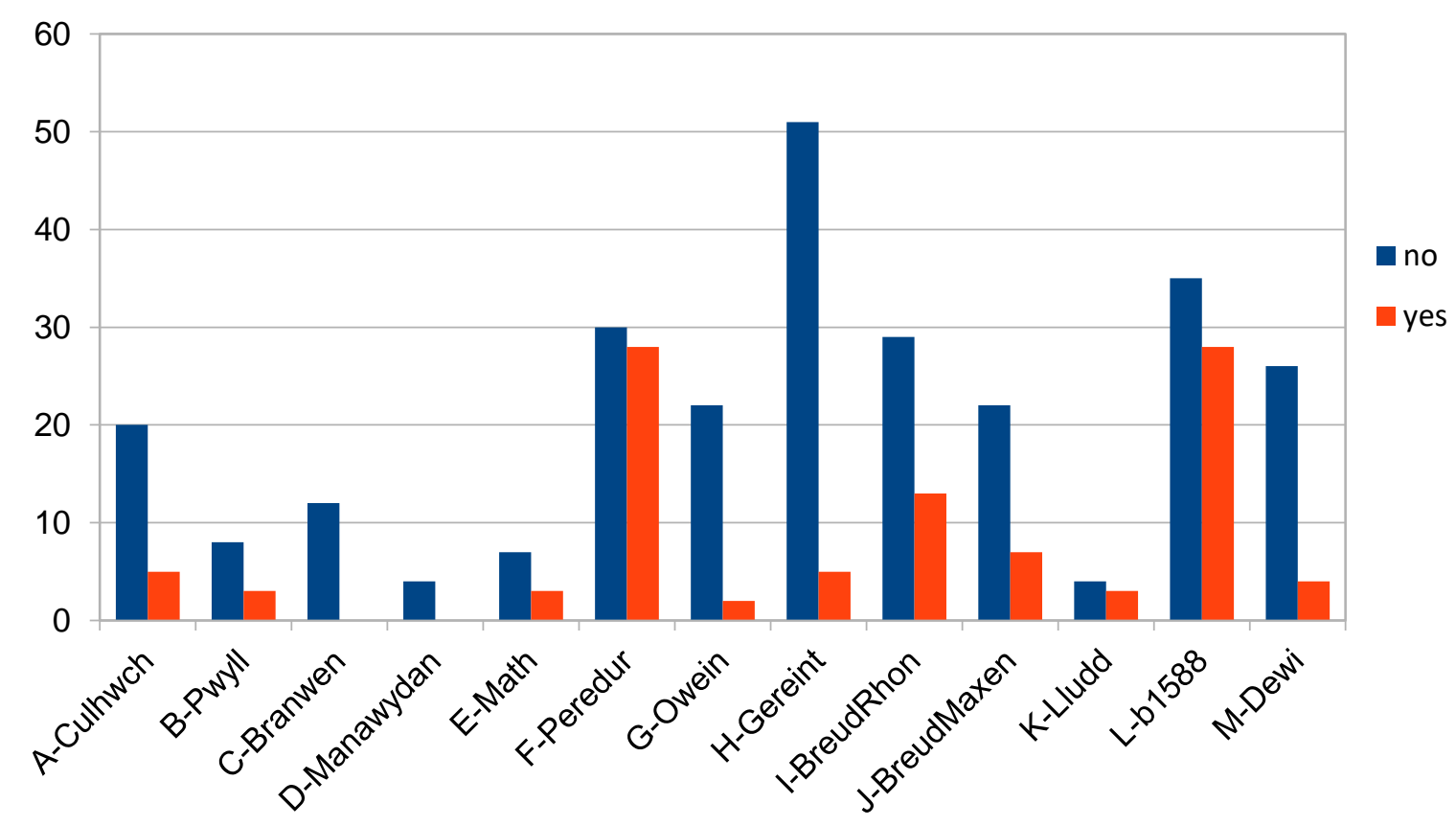

Fig. 1 Absolute numbers of agreeing ('yes') and non-agreeing ('no') adjectives in our corpus.

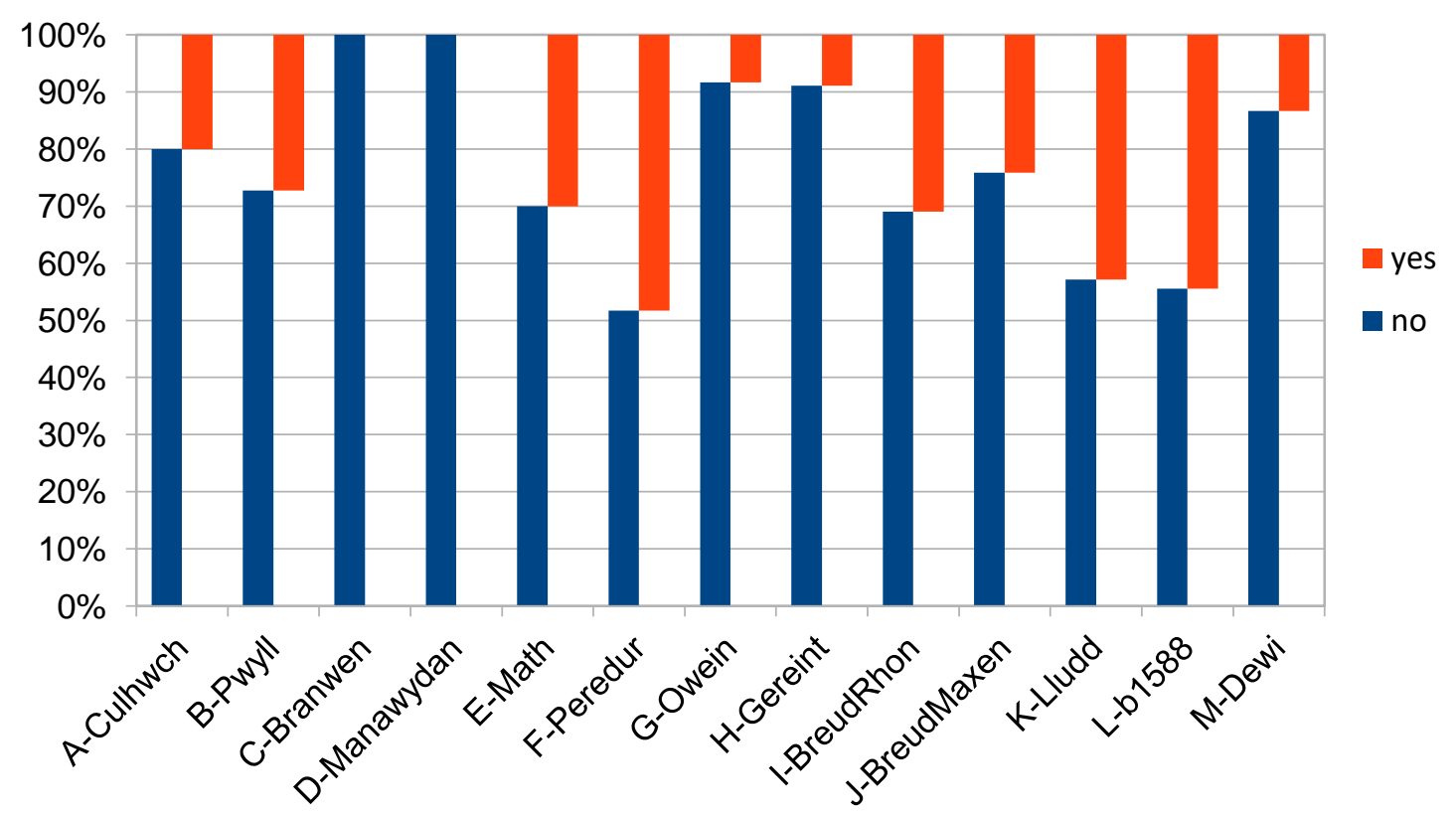

Fig. 2 Percentages of agreeing ('yes') and non-agreeing adjectives in our corpus.

\subsection{Position and function of plural adjectives}

If we look at the position and function of adjectives in native and translated prose respectively, we find some differences: 


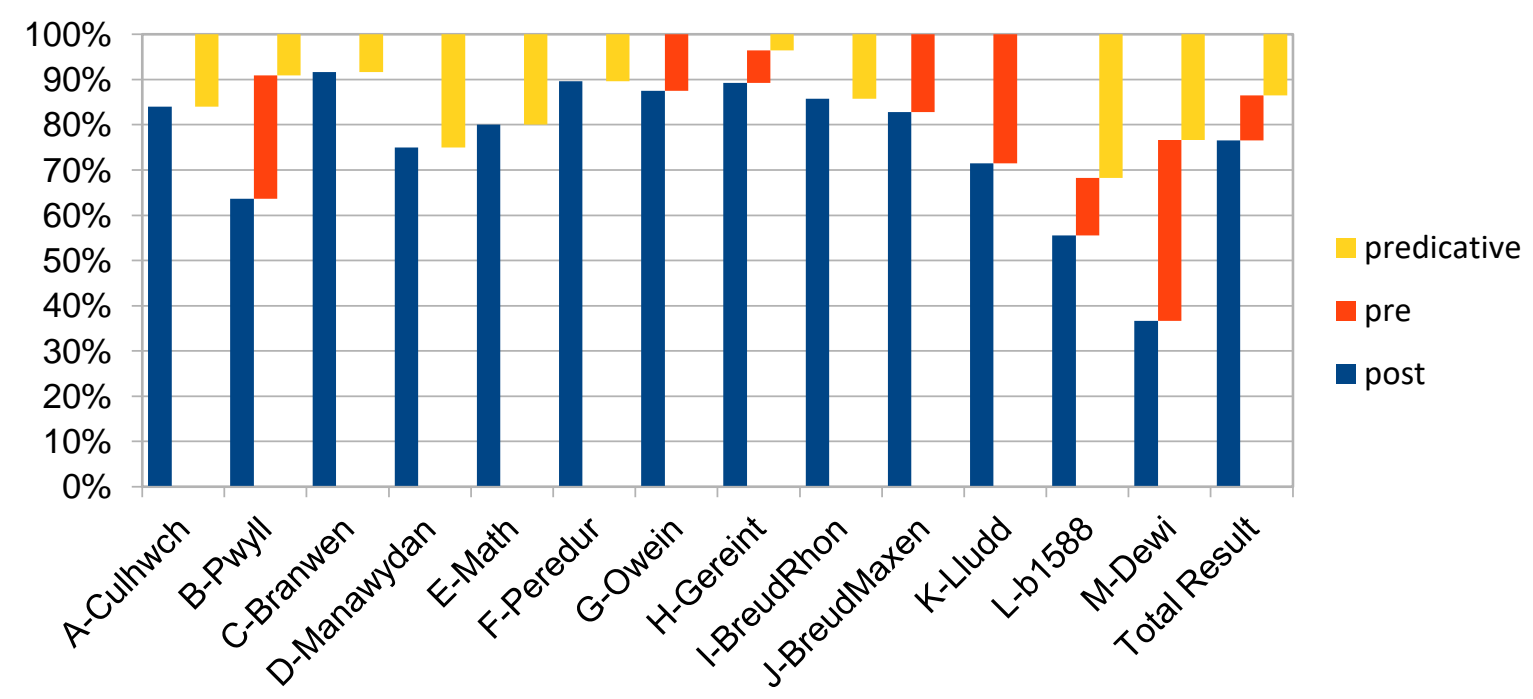

Fig. 3 Distribution of adjectives used predicatively and attributively before ('pre') and after Figure 3 Position and Function of Adjectives in Native and Translated Prose

Translated texts show a higher number of adjectives used predicatively and especially in Dewi, the number of preposed adjectives is significantly higher. If we look closer at these examples in Dewi, however, they are all with oll 'all', which occurs frequently in general in this text (see

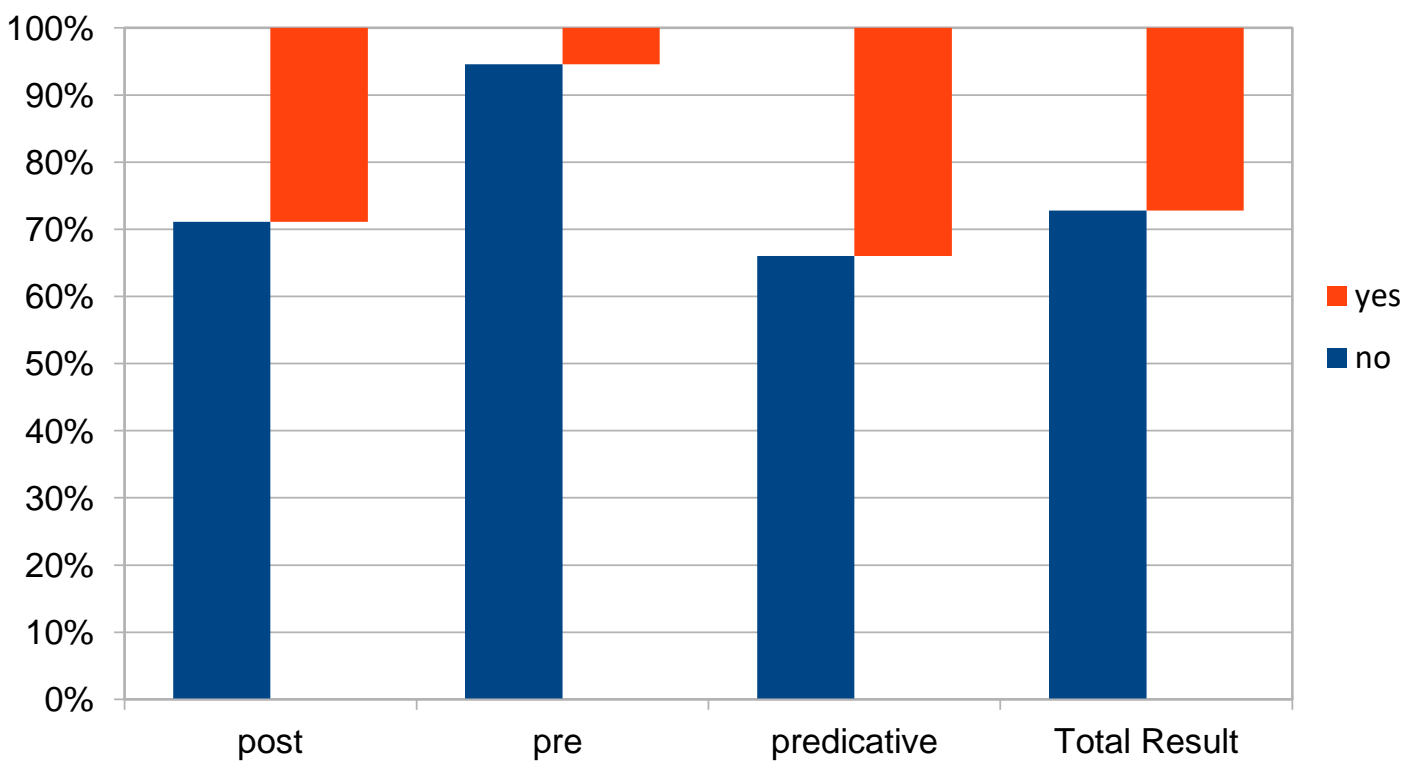

Fig. 4 Overal distribution of agreeing ('yes') or non-agreeing ('no') adjectives in different positions.

section 4.4 below). This does not, therefore, indicate a significant difference between translated and native prose. 
Fig. 4 shows the distribution of adjectives with and without agreement with attributive function, preceding the head noun (pre) or following it (post), and with predicative function. Looking at the overall results (combining both native and translated prose texts), $27 \%$ of adjectives show plural agreement in total. Pre-posing correlates with low agreement: only three examples (8\%) out of 38 have agreement. The result for predicative adjectives is somewhat surprising. As noted in the introduction, Borsley et al. (2007) state that no agreement is possible in the predicative position in Modern Welsh. This is slightly overstated, since some examples do occur, albeit rarely. A search for the plural form bychain (of bychan 'small') in the $C E G$ corpus, for instance, yields one example of predicative agreement: roeddynt yn fychain [were.3PL PRED small.PL] 'they were small'. Consider also (Mae y cyflenwadau o Wenith Lloegr a Thramor) yn fychain [PRED small.PL] '(the supplies of English and overseas wheat) are small' (Papurau Newydd: Yr Amserau 12 Nov 1851). Fig. 4 suggests that Middle and Early Modern Welsh predicative agreement is different, since the percentage of agreeing adjectives in this position is relatively high ( 17 out of 50 , or $34 \%$ agree). Thirteen of these 17 occur in the sample from the Bible translation, however, and one example is from Dewi, leaving only one example for Pwyll, Math and Peredur respectively. The Bible translation, however, also has eight predicative examples without agreement, whereas Dewi features six examples without agreement. This is, in fact, higher than the percentage for post-nominal adjectives, which is $29 \%$ ( 82 out of 284 examples agree). The difference between attributive vs. predicative function is not statistically significant (Chi-square $\chi=1.3393, \mathrm{df}=1, \mathrm{p}=0.247154$ and Fisher's exact test $\mathrm{p}$ $=0.3049$ for total number of 321 attributive [pre- and post-nominal] vs. 50 predicative adjectives modifying plural nouns, as shown in Table 1).

Our observations, then, suggest a gradual decrease in agreement in the predicative position between Middle and Modern Welsh. Even if we disregard the low number of preposed adjectives (as they mainly consist of 'special' cases, see Section 4.4 below), in Middle 
Welsh, there is no clear difference in agreement patterns between the post-nominal attributive adjectives (29\% agree in the plural) and predicative adjectives (34\% agree in the plural), while in Modern Welsh, the difference between the two appears to be significant, although this still remains to be quantified (see Introduction).

\begin{tabular}{|c|c|c|c|}
\hline & No & Yes & Totals \\
\hline Attributive (post- and pre-nominal) & 237 & 84 & 321 \\
\hline Predicative & 33 & 17 & 50 \\
\hline Totals & 270 & 101 & 371 \\
\hline
\end{tabular}

Table 1. Absolute numbers of attributive vs. predicative adjectives with (yes) and without (no) agreement.

If we look at the position of attributive adjectives in Table 2 below, there seems to be a correlation with the occurrence of plural agreement (for position vs. agreement, Chi-squared $\chi=9.3313, \mathrm{df}=1, \mathrm{p}=0.002253$ and Fisher's $\mathrm{p}=0.0012$ ); pre-posing correlates with a low likelihood for agreement. Two of the examples of pre-posed adjectives with plural agreement are with the same lexeme amrafael 'various': amrauaylon gerdeu a gvaryeu [various.PL song.PL and game.PL] 'various songs and games' (Gereint 632) and amryuaelyon gerdeu [various.PL song.PL] 'various songs' (Lludd 144). The third is amherodron mein [emperor.PL stone.PL] 'imperial stones' (BreudMaxen 57-58, 74) with the plural of amherawdr 'emperor', usually a noun, but here used like an attributive adjective, so we have included it tentatively. Although the overall number of tokens for pre-posed adjectives is low, it is interesting that plural agreement is significantly lower in this position compared to the usual post-nominal position. There are no examples of plural pre-posed adjectives in translated prose in our corpus. This is in contrast to the findings in Nurmio (forthcoming), who argues that plural pre-posed adjectives are a feature of the Brut y Brenhinedd translations, including examples of adjectives 
never attested in the plural in native texts. Not all translated texts are alike, then, and future research may confirm whether the idiosyncratic patterns found in the Brutiau are confined to these translations, or perhaps translations or a particular group of translations from this period.

$\begin{array}{llll} & \text { No } & \text { Yes } & \text { Totals } \\ \text { Post } & 202 & 82 & 284 \\ \text { Pre } & 35 & 2 & 37 \\ \text { Totals } & 237 & 84 & 321\end{array}$

Table 2. Absolute number of pre- and post-posed adjectives with (yes) and without (no) agreement.

\subsection{Adjectives with numeral phrases}

The morpho-syntax of numeral phrases in Middle Welsh is quite complex and has been shown to undergo changes over time (cf. Willis 2014; Nurmio \& Willis 2016). The head noun that is modified by a numeral is typically singular in Middle Welsh, with the exception of nouns which have numerative forms, e.g. tri meib [three boy/son.NUMERATIVE] 'three boys' (cf. sg. mab, pl. meibion, see Nurmio \& Willis 2016). The numerative system disappears by the Modern Welsh period, with the exception of blwyddyn 'year' which retains its numerative blynedd. In Modern Welsh, adjectives agree with the noun in the numeral phrase, while in Middle Welsh, adjectives are sensitive to the properties of the numeral. The following phrases exemplify this difference (from Willis 2014):
(1) $\quad y \quad$ tri $\quad$ chi
$d u(*$ duon $)$
the three.M dog.SG
black.GENERAL (*black.PL)
'the three black dogs' (Modern Welsh)
(2) deu vackwy wineuon 
two.M squire.SG auburn.PL

'two auburn-haired squires' (gwineu 'auburn') (Middle Welsh; Breuddwyd Maxen 3.7-8)

In (1), the adjective $d u$ 'black' agrees with $c i$ 'dog' in the singular, and the plural form $d u o n$ is not possible. In contrast, gwineu 'auburn' agrees with the numeral dau (MW deu) 'two' in (2), hence taking a plural form and soft mutation. Adjectival agreement, as seen in (2), does not appear to be compulsory in Middle Welsh numeral phrases, however. Table 3 shows that there are 23 instances of plural attributive adjectives in numeral phrases in our corpus; but only three remain if we do not count colours and other 'special' cases like ereill [other.PL] 'other' or ieueinc [young.PL] 'young' (see Section 4.4 for these). All of these three instances of plural adjectives are from a translated text: the 1588 Bible translation. The number of examples with agreement is significantly lower than the 51 adjectives that do not exhibit plural agreement with numerals.

These results show that, while adjectival number agreement is possible in numeral phrases, it does not occur consistently, since even commonly pluralized adjectives such as those denoting colours are not consistent in taking plural agreement: there are 11 examples of agreement in contrast to six examples of lack of agreement. ${ }^{9}$ Willis's (2014) statement that we always find plural agreement in numeral phrases if a plural form exists for the adjective in question is, therefore, too strong. ${ }^{10}$ Consider example (3):
deudec milgi
bronwyn
$d u$
twelve greyhound.SG white-breasted.GENERAL black.GENERAL
'twelve black, whitebreasted greyhounds' (Math 70-1) 
Both bronwyn 'white-breasted' and $d u$ 'black' have attested plural forms in Middle Welsh, yet these are not used here. Interestingly, ereill 'other.PL' always agrees, and Willis (2014) shows that this adjective is the slowest to change to the new system of numeral phrases, with plural agreement attested as late as the end of the eighteenth century.

\begin{tabular}{|c|c|c|c|c|c|c|}
\hline & \multicolumn{3}{|c|}{ No agreement } & \multicolumn{2}{|c|}{ Agreement } & \multirow[t]{2}{*}{ Total } \\
\hline & Post & Pre & Predicative & Post & Predicative & \\
\hline Numeral & 27 & 1 & 11 & 3 & 1 & 43 \\
\hline Numeral; colour & 6 & & & 11 & & 17 \\
\hline $\begin{array}{l}\text { Numeral; } \\
\text { conjunct }\end{array}$ & 4 & & & 1 & & 5 \\
\hline Numeral; ereill & & & & 5 & 1 & 6 \\
\hline Numeral; eur & 2 & & & & & 2 \\
\hline Numeral; ieueinc & & & & 3 & & 3 \\
\hline Total & 39 & 1 & 11 & 23 & 2 & 76 \\
\hline
\end{tabular}

Table 3. Absolute numbers of adjectives with and without agreement in numeral phrases.

\subsection{Lexemes with special behaviour}


As we stated in the introduction, the majority of Middle Welsh adjectives appear to have optional plural agreement. However, two kinds of adjectives form 'special' groups. The first group includes those that are never attested with plural forms and frequently occur both in preand post-nominal position, e.g. (h)oll 'all', unig 'unique, only (pre-nominal); alone, lonely (post-nominal)' and prif 'principal, main'.11

If we leave out the frequently-occurring ( $h$ )oll 'all' from the overall number of adjectives showing agreement, we observe differences in certain texts, but the overall

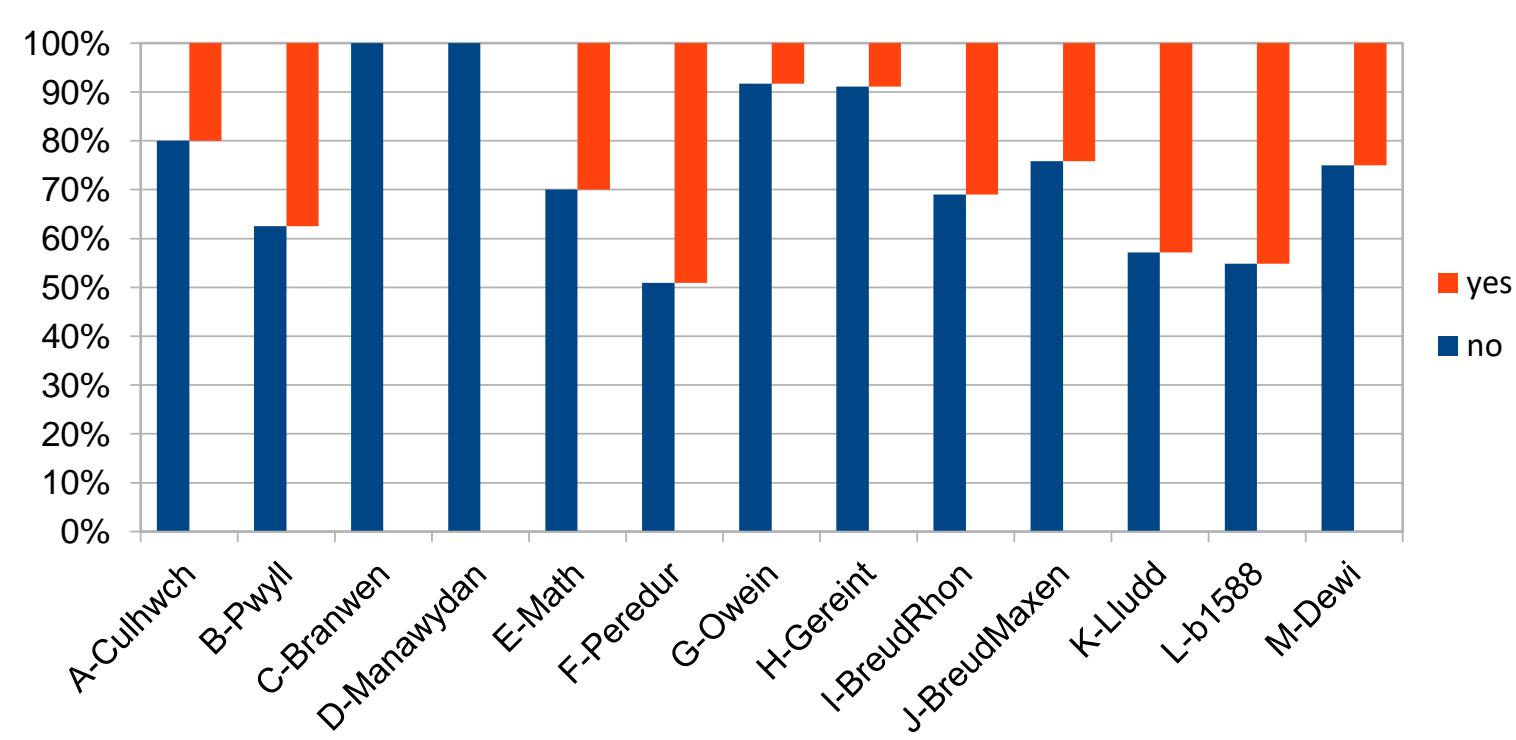

Fig. 5 Distribution of agreeing ('yes') and non-agreeing ('no') adjectives in our corpus without (h)oll 'all'.

distribution of agreement remains similar (71.5\% non-agreeing without $(h)$ oll vs. $72.8 \%$ nonagreeing with (h)oll). Dewi now has a slightly higher percentage of plural adjectives, because non-agreeing $(h)$ oll occurs frequently in this text, but the overall trend is still the same as we saw in Fig. 2 above with Peredur, Lludd and the 1588 Bible translation exhibiting the highest number of plural adjectives.

Fig. 6 below shows all adjectives which were predicted to show 'special' behaviour, i.e. agreeing more rarely or more commonly than the average: 


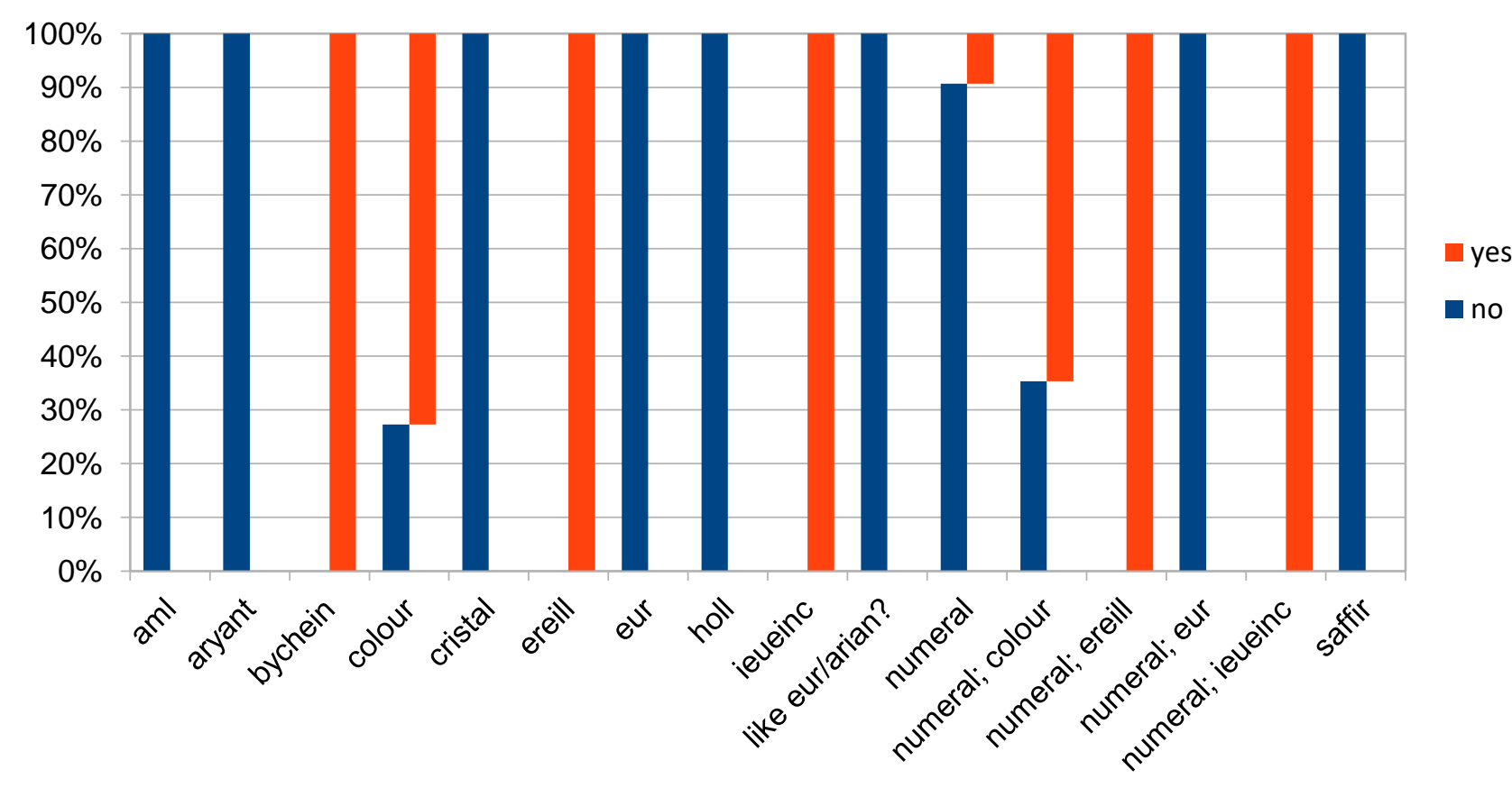

Fig. 6 Agreement with 'special' adjectives.

(H)oll 'all' and aml 'numerous, many' stand out as never having agreement and therefore belong to the first group. The second group includes adjectives that so commonly take plural agreement that they come close to having compulsory agreement when modifying a plural noun. This includes bychein 'small', ereill 'other' and ieueinc 'young' in particular. Almost twothirds of adjectives of colour, e.g. $d u$ 'black', coch 'red', etc. show plural agreement as well. On the other hand, adjectives denoting the colour of precious metals or stones, which we included as being similar to colour adjectives, show no examples of agreement: $\operatorname{aryan}(t)$ 'silver', eur 'gold', saffir 'sapphire' and cristal 'crystal' (this includes adjectives like pres 'brass; copper, bronze' that modify similar nouns as eur/aryant and thus behave in the same way, hence their label 'like eur/arian' in the above Fig. 6). These lexemes are all common as nouns denoting the precious metals in question, and this may be why they resist agreement when used as adjectives. Aryan(t) and eur in particular are often analysed as nouns instead. Perhaps phrases such as byrdeu aryant [table.PL silver.GENERAL] (BreudMaxen), for example, 
should be better analysed as two nouns, 'tables of silver' rather than 'silver tables'. A full discussion of these lexemes, however, goes beyond the scope of the present paper.

In addition to bychan 'small', some other adjectives of size, bras, pl. breision 'large, thick', cul, pl. culion 'narrow', tenau, pl. teneuon 'thin, slender' and tew, pl. tew(i)on 'thick', also agree commonly. In our corpus, all instances of these adjectives with plural nouns have number agreement: breision occurs twice, culion six times, teneuon four times, and tew(i)on three times. The number of tokens is too low to draw any conclusions, but further research on adjectival agreement should control for adjectives of size as another possible group of 'special' adjectives which commonly have number agreement.

A note on frequency is needed here. Most of the 'special' adjectives discussed here are of high frequency, as well as salient, e.g. arall 'another, other' and bychan 'small'. It may be, then, that frequency plays a role in these adjectives maintaining agreement in noun phrases while the system generally moves towards non-agreement. Crucially, however, high frequency is not a determining factor in whether an adjective commonly agrees. Some common and salient adjectives such as $d a$ 'good' and $d r w g$ 'bad' are not frequently found agreeing in the plural. In fact, $d a$ 'good' never agrees ${ }^{12}$ in any period of Welsh. Drwg 'bad' has no examples of agreement in our corpus, although one attributive example is given in GPC. Frequency and agreement are clearly connected, since the most commonly agreeing adjectives are frequent ones. However, not all frequent adjectives have plural agreement, and frequency is therefore not a strongly determining factor, but rather a factor that has helped to preserve agreement.

\subsection{Multiple adjectives modifying a noun}

Some plural nouns in our corpus are modified by more than one adjective. In such cases the question is whether they pattern similarly with single attributive adjectives. There are cases in 
which all adjectives are singular (shown in example 4) and plural (example 5), but interestingly there are several examples of a mixture of agreement and lack of agreement (example 6):

(4)

arueu trwm

ystronawl

gloyw

weapon.PL heavy.GENERAL foreign.GENERAL shining.GENERAL 'heavy, shining foreign arms' (Gereint 743)

(5)
gweisson culyon
cochyon
boy.PL
narrow.PL red.PL

'lean, red-haired boys' (Peredur 23.9)

(6) llygeit rudgochyon gwennwynic

eye.PL red.PL venomous; wrathful.GENERAL

'red, wrathful eyes' (BreudRhon 17.5)

The pattern seen in example (6) applies to all other examples in our corpus, namely the first adjective agrees while the second one has no agreement; compare arueu trymyon estronawl 'heavy, foreign weapons' (BreudRhon 15.16-17) and arueu trymyon kadarn 'heavy, steadfast weapons' (Lludd 147-8). The opposite pattern (plural noun + adjective.GENERAL + adjective.PL) does not occur in our corpus. This also seems to be the case in Modern Welsh, although we only searched for examples with bychain [small.PL] 'small', and this should be confirmed with a larger corpus. Examples found in $C E G$ include, for instance, amryw o lynnoedd bychain llonydd [some of lake.PL small.PL peaceful.GENERAL] 'some small, peaceful lakes'.

The 1588 Bible has an idiosyncratic agreement pattern not found in the other texts of our corpus, e.g. 
saith o wartheg teg yr olwg a thewono gig seven of cattle fair.GENERAL the appearance and fat.PL of meat 'seven heads of cattle fair in appearance and fat of meat' (b1588 Gen 41 2)

In this pattern, the noun phrase saith o wartheg 'seven heads of cattle' is followed by two adjectival phrases: teg yr olwg 'fair of appearance' and thewon o gig 'fat of meat'. The first adjectival phrase contains a singular adjective teg 'fair'; the second, however, contains a plural form tewon 'fat.PL'. Note that the Hebrew original has two plurals here: iphoth (mrae) [fair.PL (appearance)] 'lovely/fair of (appearance)' and brioth (bshor) [fat.PL (flesh)] 'plump/fat of (flesh)'. The pattern found in the Welsh translation requires further research, especially in relation to the Hebrew phrases being translated, but we will exclude these examples from our discussion here, since this pattern is not found more generally in Middle or early Modern Welsh.

\section{Conclusion}

In this paper, we have presented a new methodology for the systematic analysis of linguistic variation in Middle and Early Modern Welsh employing recently-annotated historical corpora, combined with new insights regarding possible differences in adjectival agreement between translated and native prose. We quantified some previously-held assumptions about adjectival agreement in Middle and Early Modern Welsh, and how this varies between different texts and textual genres and registers. We furthermore tested whether the position (pre- or post-nominal) and function (attributive vs. predicative) of adjectives made any significant difference. A small group of adjectives, such as those denoting colours, were singled out for analysis separately with the hypothesis that they would have number agreement more commonly than others. 
By looking at the texts of the 'Mabinogion corpus' of native prose, we started by establishing some basic patterns of Middle Welsh adjectival agreement. In general, lack of agreement is more common than agreement, as in Modern Welsh. We found significant differences between different lexemes, however. As predicted, the adjectives arall 'another, other', bychan 'small', and ieuanc 'young' agree very commonly; in fact they have 100\% agreement in our corpus. Adjectives denoting colours such as $d u$ 'black' also agree very commonly, although there are also examples of non-agreement. Related adjectives which denote the colours of precious metals, e.g. eur 'gold', do not pattern with adjectives for primary colours, since they never have plural agreement. Adjectives denoting size, bras 'large, thick', cul 'narrow', tenau 'thin, slender' and tew 'thick' turned out to agree in all instances in our corpus, and they should be taken into account alongside bychan 'small' in future studies.

The position of attributive adjectives was found to correlate with the likelihood for agreement. Pre-posed adjectives are less likely to agree for number than adjectives in the regular noun + adjective order. We found no examples of the type found in the Brut $y$ Brenhinedd translations (Nurmio, forthcoming) where pre-posed adjectives commonly agree with a plural head noun. As for the function of adjectives, a significant discovery is that predicative adjectives often agree with a head noun in Middle Welsh. In fact, in Middle Welsh there is no significant difference between the attributive and predicative positions, and the likelihood for agreement. This suggests that agreement in the predicative position has declined between Middle and Modern Welsh, where predicative agreement is all but gone, perhaps with some exceptions. The agreement of adjectives in Modern Welsh remains an area in need of quantitative study, however, so we cannot currently compare the two stages in detail.

We furthermore discovered differences between different texts of the native corpus, but these did not adhere to any of the patterns that might have been expected. Culhwch ac Olwen does not stand out in the corpus by, for instance, having a higher proportion of agreement, 
which might have been expected given its assumed earlier date. The 'Three Romances' did not pattern as a group from other texts of the Mabinogion corpus, so this particular linguistic feature does not suggest that these are significantly different. Instead, Peredur stands out on its own as having a high percentage of agreement, but this is not shared by Gereint and Owein. The 'fluid' nature of Peredur might play a role in these findings, but further research on adjectival agreement in different manuscripts of the texts is necessary before we can draw such a conclusion.

As regards genre and register, we tested the hypothesis that translated texts feature a higher proportion of adjectival number agreement than native prose, which is suggested by previous scholarship on some medieval translated texts. We also explored a related observation often made, namely that translated prose has a higher proportion of attributive adjectives preceding the noun they modify, instead of the regular order of noun followed by the adjective. Our main finding was that there was no clear difference between native and translated texts in this corpus. This suggests that translation texts need to be considered not as a uniform group, since our findings did not accord with previous work on texts such as the Brut y Brenhinedd translations. The 1588 Bible translation differs in an interesting respect from the other texts of our corpus. Looking specifically at numeral phrases, only 'special' adjectives like bychan 'small' or colour adjectives agree in number in numeral phrases in the other texts. In the Bible translation, however, we find agreement with adjectives outside this group (see Section 4.3 above). More work is needed on agreement in the 1588 Bible translation, and such work should consider its relation to the Hebrew and Greek originals. These preliminary findings regarding translated and non-translated texts should, however, be treated with caution. Since the systematic annotation and manual correction of medieval texts is a time-consuming task, we were only able to test these hypotheses on the currently-available texts. It should be noted that there is a considerable time difference between, for example, the oldest texts of the native 
Mabinogion and the late-sixteenth-century Bible translation. In the course of these two centuries, the Welsh language has most certainly undergone several changes. In future research, we therefore hope to expand our annotated corpora and include both translated and nontranslated texts from each of the different periods.

To sum up, we have set out the basic picture of adjectival agreement in a group of Middle Welsh native prose texts and a sample of translations from the period around the end of the Middle Welsh period. We found interesting differences between texts, although these did not correspond to many of our hypotheses or assumptions about how certain texts group together. We hope to have demonstrated how we can explore the interaction of linguistic features and textual factors in Middle Welsh better with the availability of newly-developed annotated corpora. This paper has raised a number of questions which will hopefully be addressed in further work on both Middle and Modern Welsh. An important one among these is the question whether medieval translation texts can be considered to be a genre in any uniform sense, or whether there are simply groupings of texts sharing certain characteristics which are not, however, shared by all other translated texts.

\section{Notes}

${ }^{1}$ A reviewer rightly points out that it is not clear whether translation texts form a single 'genre', since there are several kinds of translated texts (e.g. historical, religious), or whether they would be better regarded as a linguistic register. We would like to leave this question open until further work has been conducted on translation texts beyond our current, fairly small sample. Such work will throw more light on linguistic similarities and differences between translated texts of different kinds and of different dates and aid in deciding how exactly they should be grouped together. We would like to thank the two anonymous reviewers for the Journal of Celtic Linguistics for their suggestions, and we are also thankful to Paul Russell for commenting on an earlier version of this article.

${ }^{2}$ The other examples are gwrthbwysau arall 'other counter-pressures' and moddion arall 'other medicine'. Moddion, the plural of modd 'mode, way, means', has been somewhat lexicalised in the meaning 'medicine', and hence it is less clear whether it was still understood as plural in the example given here. There are also examples 
of the general form arall with the idiosyncratic noun pobl '(a) people, nation', which can take both singular and plural agreement (Thomas 2006: 153).

${ }^{3}$ Lludd a Llefelys is traditionally accepted as 'native prose' as it is part of the Mabinogion corpus. A reviewer pointed out to us that the actual transmission history of this particular text is more complex since it appears to be a more learned write-up of a traditional (oral) tale. There are only seven relevant tokens in this text for the current adjective case study and the distribution of position and agreement patterns does not differ from the other texts of the Mabinogion corpus. No further conclusions can be drawn based on this case study alone since the number of tokens is so low.

${ }^{4}$ For this sample study, we have only tagged the edited texts based on the White Book versions of the native Welsh tales. The Red Book is from a slightly later date, and has often been noted to be more innovative linguistically, so it might differ in terms of adjectival agreement. Our next step in this ongoing research will therefore be a systematic comparison of the present findings from the White Book with the Red Book manuscript, as soon as we have developed a tagged version of the latter.

${ }^{5}$ Absolute counts are based on the number of adjectives that could potentially show agreement because they are modifying a plural head noun. A plural head noun that is modified by multiple adjectives will thus be counted more than once. See section 5 below on the possible correlation between (the lack of) agreement and occurrence of multiple adjectives.

${ }^{6}$ The labels on the $\mathrm{X}$-axis of the chart refer to the following Middle Welsh native prose texts: A - Culhwch (Culhwch ac Olwen), B - Pwyll (Pwyll Pendefig Dyfed), C - Branwen (Branwen ferch Llyr), D - Manawydan (Manawydan fab Llyr), E - Math (Math fab Mathonwy), F - Peredur (Peredur fab Efrog), G - Owein (Owein, neu Iarlles y Ffynnon), H - Gereint (Gereint ac Enid), I - BreudRhon (Breudwyt Ronabwy), J - BreudMaxen (Breudwyt Maxen), K - Lludd (Cyfranc Lludd a Llefelys) and the following translated texts: L - b1588 (the sixteenth-century translation of the Old and New Testament), M - Dewi (Buchedd Dewi).

${ }^{7}$ Peredur is, furthermore, argued to consist of two distinct parts, with the first part ending with Peredur's wedding to the empress, which is indicated as the end of the story in one of the four medieval manuscript versions, Peniarth 7, with the words Ac y velly y t(er)vyna kynnyd Paredur ap Efrawc 'and thus ends the development of Peredur son of Efrawg' (Vitt 2010: 204-5). We checked the distribution of all examples with and without adjectival agreement in both parts, but found no significant difference (Fisher's exact: $\mathrm{p}=0.0862$ of Agreement vs. Part 1/Part 2). 
${ }^{8}$ Note that the percentage of plural adjectives in Pwyll and Lludd look equally high, but the absolute numbers of instances in these texts is very low with only three plural adjectives each. Lludd is not only a text with a complicated historical transmission (see footnote 3), it is also much shorter than any other text in our corpus. From a methodological point of view, it is important to bear in mind that topic as well as the length of the text can have an effect on 'the opportunity of use' of a linguistic component, e.g. a lexical item or a specific construction (see Buttery \& Caines (2012) on a detailed study of adverb usage in learner corpora).

${ }^{9}$ The adjectives bronwyn 'white-breasted' and brych 'speckled' were treated as colour adjectives since they only ever describe garments or animal coats.

${ }^{10}$ Demonstratives behave differently from adjectives in numeral phrases; they are sensitive to the properties of the numeral in both Middle and Modern Welsh, and therefore have plural agreement with 'two' and above (see Willis 2014, Mittendorf \& Sadler 2005).

${ }^{11}$ These are treated as adjectives for now, but we are aware that there might be alternative analyses. The English lexemes all, another, other and various are analysed as determinatives by Huddleston \& Pullum (2002: 374, 391-2). Welsh prif 'principal, main', on the other hand, corresponds to English 'attributive-only' adjectives (which are never found in a predicative position), a subsection of which is made up of 'primacy adjectives' such as chief, prime and main (Huddleston \& Pullum 2002: 553, 558).

${ }^{12} \mathrm{Da}$ 'good' has two plural forms, but these are always used as nouns and not in attributive agreement: deon 'noblemen' and daoedd 'goods' (GPC: s.v. da, deon ${ }^{2}$ ).

\section{References}

\section{Corpora}

Ellis, N. C., C. O’Dochartaigh, W. Hicks, M. Morgan \& N. Laporte (eds.) 2001. Cronfa Electroneg o Gymraeg (CEG): A 1 Million Word Lexical Database and Frequency Count for Welsh. Bangor University. www.bangor.ac.uk/canolfanbedwyr/ceg.php.en (CEG) (accessed 14/8/2017).

Isaac, G. R., S. Rodway, S. Nurmio, K. Kapphahn \& P. Sims-Williams (eds.) 2013. Rhyddiaith Gymraeg o Lawysgrifau'r 13eg Ganrif: Fersiwn 2.0. Aberystwyth University. https://cadair.aber.ac.uk/dspace/handle/2160/5811 (accessed 19/6/2019). 
Papurau Newydd Cymru Arlein, papuraunewydd.llyfrgell.cymru (Papurau newydd) (accessed 14/8/2017).

\section{Primary texts}

Bromwich, R. \& D. Simon Evans (eds.). 1992. Culhwch ac Olwen: An Edition and Study of the Oldest Arthurian Tale. Cardiff: University of Wales Press. (Culhwch)

Roberts, B.F. (ed.). 2005. Breudwyt Maxen Wledic. Dublin: Dublin Institute for Advanced Studies. (BreudMaxen)

Evans, D. Simon (ed.). 1965. Buchedd Dewi. Cardiff: University of Wales Press. (Dewi)

Goetinck, G.W. (ed.) 1976. Historia Peredur vab Efrawc, Cardiff: University of Wales Press. (Peredur)

Hughes, I. (ed.) 2007. Manawydan Uab Llyr: Trydedd Gainc y Mabinogi. Second edition. Cardiff: University of Wales Press. (Manawydan)

Hughes, I. (ed.). 2013. Math Uab Mathonwy: The Fourth Branch of the Mabinogi. Dublin: Dublin Institute for Advanced Studies. (Math)

Morgan, W. (trans.). 1588. Y Beibl Cys-segr-lan. Sefyr Hen Destament, a'r Newydd, Imprinted at London by the Deputies of Christopher Barker. Available online at www.llgc.org.uk/big/index_s.htm and in the Historical Corpus of Welsh by David Willis \& Ingo Mittendorf: http://people.ds.cam.ac.uk/dwew2/hcwl/menu.htm (b1588)

Richards, M. (ed.). 1948. Breudwyt Ronabwy; allan o'r Llyfr Coch o Hergest. Cardiff: University of Wales Press. (BreudRhon)

Roberts, B.F. (ed.). 1975. Cyfranc Lludd a Llefelys, Dublin: Dublin Institute for Advanced Studies. (Lludd)

Thomson, D.S. (ed.). 1961. Branwen Uerch Lyr, Dublin: Dublin Institute for Advanced Studies. (Branwen) 
Thomson, R.L. (ed.). 1957. Pwyll Pendeuic Dyuet, Dublin: Dublin Institute for Advanced Studies. (Pwyll)

Thomson, R.L. (ed.). 1968. Owein or Chwedyl Iarlles y Ffynnawn, Dublin: Dublin Institute for Advanced Studies. (Owein)

Thomson, R.L. (ed.). 1997. Ystorya Gereint Uab Erbyn, Dublin: Dublin Institute for Advanced Studies. (Gereint)

Williams, I. (ed.). 1930. Pedeir Keinc y Mabinogi, Cardiff: University of Wales Press.

\section{Secondary literature}

Awbery, G. 2014. Problems with Phrasal Compounds in Welsh, Journal of Celtic Linguistics 15, 3-38.

Borsley, R.D., M. Tallerman, \& D. Willis. 2007. The Syntax of Welsh. Cambridge Syntax Guides, Cambridge: Cambridge University Press.

Buttery, P. \& Caines, A. 2012. Normalising Frequency Counts to Account for 'Opportunity of Use' in Learner Corpora. In: Tono, Y., Kawaguchi, Y., and Minegishi, M. (eds.), Developmental and Crosslinguistic Perspectives in Learner Corpus Research. Amsterdam: John Benjamins, pp. 187-204.

Charles-Edwards, T.M. 2001. The Textual Tradition of Medieval Welsh Prose Tales and the Problem of Dating. In: B. Maier, S. Zimmer \& C. Batke (eds.), 150 Jahre “Mabinogion”-Deutsch-Walisische Kulturbeziehungen. Tübingen: Niemeyer, 23-39.

Cordo Russo, L. 2014. Translational Procedures in Cân Rolant, the Middle Welsh Translation of La chanson de Roland'. Brathair 14(2), 109-128.

Daniel, R. I. (ed.) 1995. Ymborth yr Enaid: Gyda Rhagymadrodd a Nodiadau. Cardiff: University of Wales Press. 
Davies, S. 1998. Written Text as Performance: the Implications for Middle Welsh Prose Narratives. In: H. Pryce (ed.), Literacy in Medieval Celtic Societies. Cambridge: Cambridge University Press, pp. 133-48

Evans, D.S. 1964. A Grammar of Middle Welsh. Dublin: Dublin Institute for Advanced Studies. Falileyev, A. 2000. Etymological Glossary of Old Welsh. Tübingen: Max Niemeyer Verlag. Harlos, A., Poppe, E., \& Widmer, P. 2014. Decoding Middle Welsh Clauses or 'Avoid Ambiguity'. Indogermanische Forschungen 119(1), 125-48.

Huddleston, R. \& G.K. Pullum. 2002. The Cambridge Grammar of the English Language. Cambridge: Cambridge University Press.

Huws, D. 2000. Medieval Welsh Manuscripts. Cardiff \& Aberystwyth: University of Wales Press \& The National Library of Wales.

Jørgensen, A.R. 2012. Plural Suppletion in Adjectives - the Case of the Plural of Breton and Cornish bihan 'little'. Conference paper presented at 'Synchrony and Diachrony: Variation and Change in Language History', Oxford, 2012.

Lloyd-Morgan, C. 1991. French Texts, Welsh Translators. In: R. Ellis (ed.), The Medieval Translator II. London: Centre for Medieval Studies, Queen Mary and Westfield College, University of London, pp. 45-63.

Lloyd-Morgan, C. 2004. Medieval Welsh Tales or Romances? Problems of Genre and Terminology. Cambrian Medieval Celtic Studies 47, 41-58.

Luft, D. 2016. Tracking Ôl Cyfieithu: Medieval Welsh Translation in Criticism and Scholarship. Translation Studies 9(2), 168-82.

Meelen, M. 2016. Why Jesus and Job Spoke Bad Welsh: The Origin and Distribution of V2 Orders in Middle Welsh. Utrecht: LOT dissertation series. Available online at https://openaccess.leidenuniv.nl/handle/1887/40632. 
Meelen, M. forthcoming. Annotating Middle Welsh: POS Tagging and Chunk-Parsing a Partial Corpus of Native Prose. In: E. Lash (ed.) Proceedings of the Maynooth Colloquium on Celtic Computational Linguistics.

Mittendorf, I. \& L. Sadler. 2005. Numerals, Nouns and Number in Welsh NPs. In: M. Butt \& T. Holloway King (eds.), Proceedings of the LFG05 Conference, University of Bergen. Stanford, California: CSLI Publications. 294-312.

Nurmio, S. 2017. The Development and Typology of Number Suppletion in Adjectives, Diachronica 34(2), 127-74.

Nurmio, S. forthcoming. Grammatical Number in Welsh: Diachrony and Typology.

Nurmio, S. \& D. Willis. 2016. The Rise and Fall of a Minor Category: The Welsh Numerative, Journal of Historical Linguistics 6(2), 297-339.

Parina, E. 2017. The Language of Middle Welsh Religious Texts. Poster presented at the Ninth Celtic Linguistics Conference, Cardiff University, 9/1/2017. https://www.unimarburg.de/fb10/iksl/sprachwissenschaft/forschung/projekte/projekt-parina/poster.pdf (accessed 28/8/2018)

Plein, K. \& E. Poppe. 2014. Patterns of Verbal Agreement in Historia Gruffud Vab Kenan: Norm and Variation, Études celtiques 40, 145-63.

Poppe, E. 2014. How to Achieve an Optimal Textual Fit in Middle Welsh Clauses. Cambrian Medieval Celtic Studies 68, 69-100.

Poppe, E. 2016. Towards a Linguistic Profile of the Medieval Welsh Transitus Mariae. Paper presented at the Early Irish and Celtic Studies Research Seminar, Maynooth University, 12/1/2016. Available online at:

https://www.uni-marburg.de/fb10/iksl/sprachwissenschaft/forschung/projekte/projektparina/maynooth.pdf (accessed 28/8/2018). 
Poppe, E. \& R. Reck. 2006 \& 2008. A French Romance in Wales: Ystorya Bown o Hamtwn. Processes of Medieval Translations. Zeitschrift für celtische Philologie 55, $122-80$ [part 1]; 56, 129-64 [part 2].

Rodway, S. 2013. Dating Medieval Welsh Literature: Evidence from the Verbal System. Aberystwyth, CMCS Publications.

Russell, P. 1995. An Introduction to the Celtic Languages. London: Longman.

Russell, P. 2003. Texts in Contexts: Recent Work on the Medieval Welsh Prose Tales. Cambrian Medieval Celtic Studies 45, 59-72.

Thomas, P.W. 2006. Gramadeg y Gymraeg. Third edition. Cardiff: University of Wales Press.

Thomas, R. J., et al. (eds.), 1950-. Geiriadur Prifysgol Cymru. Cardiff: University of Wales Press (second edition from 2003-, ed. G. A. Bevan \& P. J. Donovan et al., available online at http://www.geiriadur.ac.uk (GPC) (accessed 31/8/2018).

Vitt, A.M. 2010. Peredur Vab Efrawc: Edited Texts and Translations of the MSS Peniarth 7 and 14 Versions. Aberystwyth University MPhil thesis. http://hdl.handle.net/2160/6118 (accessed 23/10/2017).

Willis, D. 2014. Maintaining the Historical Directionality of Syntactic Change in Numeral Phrases. Paper presented at the Sixteenth Diachronic Generative Syntax Conference, Research Institute for Linguistics, Hungarian Academy of Sciences, Budapest. 